\title{
Impact of physical health and exercise activity on online user experience: Elderly people and high risk for diabetes
}

\author{
Harri Oinas-Kukkonen ${ }^{1}$, Li Zhao ${ }^{1}$, Heidi Enwald ${ }^{2}$, Maija-Leena Huotari ${ }^{2}$, Riikka \\ $\mathrm{Ahola}^{3}$, Timo Jämsä ${ }^{3}$, Sirkka Keinänen-Kiukaanniemi ${ }^{4}$, Juhani Leppäluoto ${ }^{5}$, Karl- \\ Heinz Herzig ${ }^{5}$
${ }^{1}$ University of Oulu, Faculty of Information Technology and Electrical Engineering, Oulu Advanced Research on Service and Information Systems
${ }^{2}$ University of Oulu, Faculty of Humanities, Information Studies
${ }^{3}$ University of Oulu \& Oulu Univ. Hospital, Medical Research Center, Inst. Biomedicine
${ }^{4}$ University of Oulu \& Oulu Univ. Hospital, Inst. of Health Sciences \\ ${ }^{5}$ University of Oulu \& Oulu Univ. Hospital, Medical Research Center, Inst. \& Biocenter Oulu \\ \{firstname.lastname doulu.fi
}

\begin{abstract}
This article studies how an individual's physical wellbeing contributes to one's online user experience. The study subjects were elderly people at high risk for type 2 diabetes. The results suggest that the web usage experience of these pre-diabetic individuals is related to their physical health status and level of physical activity. Those with a better physical health status were more likely to feel ease of orientation in their web usage, and those with more frequent regular physical activity were more likely to perceive pleasure in navigating the web. In practice, variation in physical health and activity levels between individuals could, and should. be addressed in designing systems and services. In more general, studying user experience on par with biochemical measurements provides an exciting combination of research methods and paves the way for new design practices.
\end{abstract}

Keywords: user experience, flow, physical health, physical exercise

\section{Introduction}

Globally, hundreds of millions of people suffer from diabetes [1-7]. In health promotion and lifestyle counseling, perceived personal relevance of health information may help engage individuals and create opportune conditions for influencing a user [8-12]. In other words, the aim is to produce individualized communication so that a user could think 'This applies to me' [9, p. 55]. Tailoring enhances cognitive conditions for human information processing and acceptance, and a typical aim of it is simply to increase attention and comprehension [10]. A previous study among individuals at high risk for diabetes showed that those whose physical health status was poor desired receiving tailored information on nutrition and physical activity more frequently than those with a better physical health status $[13,14]$. This article investigates the relationship between physical health status, physical exercise, and online user engagement. 


\section{Background}

In order for interventions to be genuinely influential, carefully designed and tailored behavior change support systems with the ultimate aim of engaging users in their daily lives and persuading them to adopt and maintain healthier behaviors are called for [1521]. There is growing interest towards using the flow concept for understanding user experience in information systems' (IS) [see, e.g., 22-26]. Originally, flow was described as a holistic sensation that people feel when they act with total involvement [23]. More recently, flow has been defined as a state, which occurs when navigating in an information space and which is intrinsically enjoyable, self-reinforcing and accompanied by a loss of self-consciousness; it can exist in both experimental and goaloriented types of behavior $[17,27]$. The flow user experience can be made better through interactive relationships between a user's individual characteristics, the characteristics of the artifact, and the characteristics of the primary task [18]. Support for orientation and navigation capabilities have been suggested as key for positive user experience [28]. In addition, an immersive use of such services requires the user's focused attention [29].

Specifically, in the field of healthcare, continuous measuring of physical health status and physical activity adds to the rapid growth of health-related big data. Large data archives can provide information about an individual's health status, which may be objectively measured physiologically and biochemically. In many cases, these objective measurements provide more reliable information about health status than self-reported subjective data [30, 31]. Health behavior change support systems [15] can now be built on top of objective measurements; for example, objective physical activity measurements with accelerometers and pedometers can be used to determine patterns of physical activity behavior [32,33]. A systematic review by [34, compare with 35] shows a noticeable increase in the amount of objectively measured physical activity in these types of interventions.

\section{Research model and hypotheses}

Online users' feeling of being fully focused and perception of ease of orientation and pleasure of navigation are key components of the Webflow model [21,28]. These user experience constructs have been adopted for the study here in the context of web-based health applications. An individual's physical health status and physical exercise are then incorporated into in the research model, together with these Webflow components.

User experience. Previous Webflow studies have found that perceived ease of orientation and perceived pleasure of navigation have a direct effect on gaining an optimal user experience, whereas, somewhat surprisingly, perceived ease of use and usefulness [cf. 36] were not found to have a direct influence on user experience [28]. If an individual feels that s/he can easily be oriented in web navigation, it is more likely for him/her to enjoy the web navigation. Otherwise, if s/he feels it is difficult to do so, that will negatively affect the perceived pleasure of navigation. Focused attention [17, 27] influences the ease of orientation and pleasure of navigation. In the contemporary information and socially-laden web, cognitive overload has become a greater challenge than ever before, resulting in attention focus becoming less and less of a commodity for users. 
Physical health status. When an individual is in a bad health status, it will be difficult for him/her to focus his/her attention on a particular task, because his/her bad health status (such as the pain) may distract him/her from the task. Known risk factors for type 2 diabetes and cardiovascular diseases are obesity, high level of low-density lipoprotein (LDL) and low level of high-density lipoprotein (HDL) cholesterol. Lipid markers are well-established predictors of vascular disease. The most frequently measured lipid variables are total cholesterol, HDL cholesterol, LDL cholesterol, and triglycerides. By following and preventing abnormalities in this lipid homeostasis, diseases such as heart diseases and type 2 diabetes can be prevented. In this study, the individuals' physical health status is indicated by the state of their lipid metabolism, technically by levels of total cholesterol and total triglycerides, as well total fatty acids measured from a blood sample.

Physical exercise activity level. It is commonly believed that regular physical exercise, such as brisk walking, peaceful swimming, performing fitness gymnastics, brisk cycling, ice skating, or skiing, is good for one's health. Prior studies have shown that lifestyle changes such as increased physical exercise and weight loss can reduce the risk of diabetes by approximately $58 \%[5,37]$. It has been found that an adequate level of regular moderate-intensity physical exercise reduces the risk of numerous chronic diseases, preserves health and functioning (both physical and mental) into old age, and extends longevity [e.g., 38]. Aerobic exercise of 60 minutes three times a week for 12 months can even improve maximal oxygen uptake and leg muscle strength, and decrease waist circumference, LDL cholesterol, and total cholesterol in premenopausal women [39]. Thus, a person who does physical exercise regularly is more likely to improve his/her physical health status. After doing such exercise people feel refreshed and revitalized. Thus, this individual is more likely to perceive pleasure in navigating the web. If a person exercises regularly, he or she is more likely to feel good, and consequently more likely to perceive pleasure in navigating the web, as noted above. In this case, the effect of focused attention becomes less critical in resulting in enjoying web navigation. In other words, the impact of focused attention on the perceived pleasure in web navigation becomes less salient. Therefore, the physical exercises moderate the impact of focused attention on a user's perception of web navigation.

Table 1. Research hypotheses.

H1: An individual who feels ease of orientation in web usage is more likely to perceive pleasure in navigating the web.

$\mathrm{H} 2$ : An individual who is able to focus on his/her primary activity when using the web is more likely to feel ease of orientation in web usage.

H3: An individual who is able to focus on his/her primary activity when using the web is more likely to perceive pleasure in navigating the web.

H4: An individual with a poor physical health status is more likely to have difficulty focusing on his/her task when using web services.

H5: An individual with a poor physical health status is less likely to feel ease of orientation in web services.

H6: An individual who does physical exercise regularly is more likely to have a good physical health status.

$\mathrm{H} 7$ : An individual who does physical exercise regularly is more likely to perceive pleasure in navigating the web.

H8: The positive relationship between focused attention and the perceived pleasure in web navigation is contingent upon how much physical exercise an individual regularly does, in such a way that this positive relationship will be stronger for the individual who does less physical exercise and weaker for the individual who regularly does more physical exercise. 


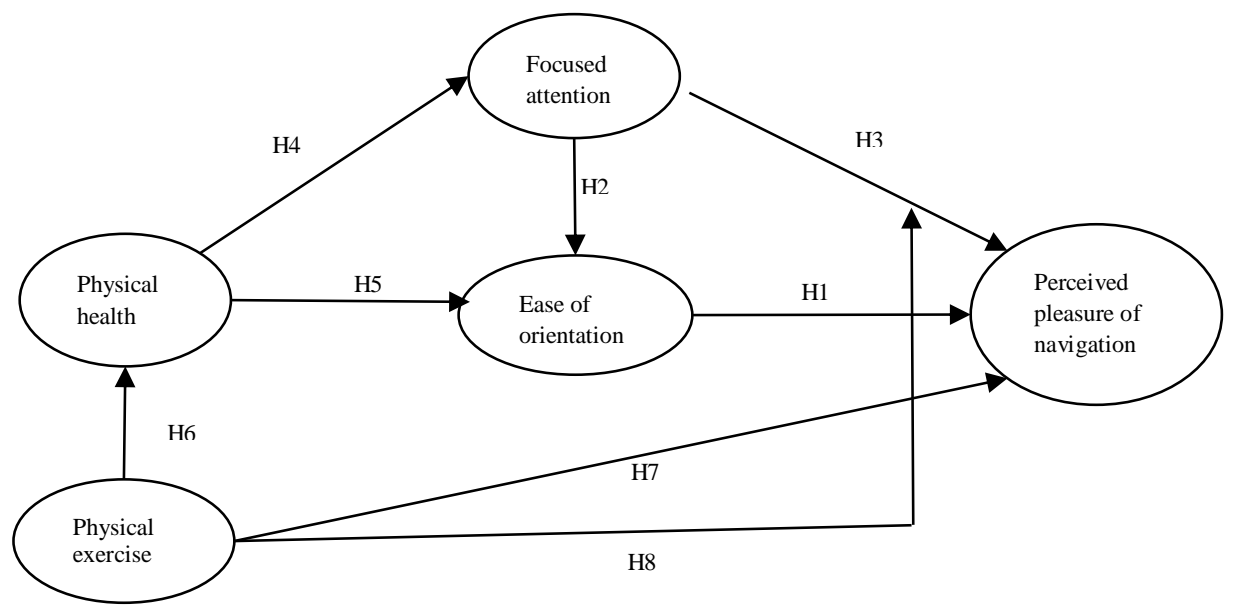

Fig. 1. Research model.

\section{$4 \quad$ Research setting}

The empirical study was conducted among individuals with a high risk for type 2 diabetes, who volunteered to participate in a physical activity intervention trial known as PreDiabEx carried out in Northern Finland [40]. Study subjects were recruited from outpatient diabetes clinics in the Oulu Deaconess Hospital and the City of Oulu. The survey was conducted at the same time when conducting the biochemical measurements.

The user experience data reported here were collected through a questionnaire survey among individuals with a high risk for type 2 diabetes. The data related to the flow user experience focus on recognizing and explaining the antecedents of a positive user experience. The questionnaire also assessed background information (age, gender, marital status, education, employment) and information about physical activity (specifically, self-reported frequency of moderate-intensity physical exercise). The blood tests for lipid markers were conducted at the same time. The responses for the questionnaires were collected on this occasion by nurse researchers, and when necessary, they also helped the participants fill in the questionnaires. Based on previous studies [21, 28], the first author designed the survey questions related to navigation, orientation, and focused attention.

Of the 72 original participants, 69 responded to the survey. However, 16 survey participants did not answer the questions about Perceived Ease of Orientation, Pleasure of Navigation and Focused Attention. Thus, the final sample size is 53, for a response rate of $73.6 \%$. The average age of the respondents was 60 years. The majority (62\%) of the respondents were 60 years or older, and $72 \%$ were women. In addition, $79 \%$ were married or living with a partner. Nearly half only had primary level education $(45 \%)$, $30 \%$ had completed secondary education, and about $25 \%$ higher education. The desired level of total cholesterol for pre-diabetic individuals was considered to be less than 4.5 $\mathrm{mmol} / \mathrm{l}$ and the desired level for total triglycerides was $2.0 \mathrm{mmol} / \mathrm{l}$, whereas for total fatty acids there is no similar generally agreed threshold. The measured average serum 
cholesterol levels were $5.08 \mathrm{mmol} / \mathrm{l}$, and total triglycerides and total fatty acids were $1.35 \mathrm{mmol} / \mathrm{l}$ and $10.79 \mathrm{mmol} / \mathrm{l}$, respectively. Thus, the average for total cholesterol exceeded the desired level. The self-reported frequency (times/week) of moderateintensity physical exercise per week was used as a measure of this variable.

\section{Data analysis and results}

Because the sample size for this study is small, partial least squares (PLS) was used to test the research model and hypotheses [42], given that PLS is less affected by small sample sizes [43]. PLS is a structural equation modeling technique that simultaneously evaluates the reliability and validity of the measures of theoretical constructs and tests the relationships among constructs [43]. In the research model, the dependent latent variable with the largest number of independent latent variables impacting it is "Perceived Pleasure of Navigation," which is impacted by three independent variables (Focused Attention, Ease of Orientation, and Physical Exercise). Therefore, the least sample size is 30 (equal to 10 times 3 ). In what follows, the PLS model is analyzed and interpreted in two stages: the assessment of the measurement model and the assessment of the structural model.

Measurement Model. PLS was used to calculate the composite scale reliability (CR) $[43,44,45]$ and average variance extracted (AVE) $[43,44]$. CR was used to assess the inter-item reliability by measuring the internal consistency of a given block of indicators [45]. The AVE was used to examine the convergent validity of the constructs, which attempted to measure the amount of variance that a latent variable component captured from its indicators relative to the amount due to measurement error. Cronbach's alphas exceeded 0.70 . The lowest CR was 0.87 , compellingly exceeding the recommended " 0.70 " threshold value [44]. The AVE of all measures was much higher than the cut-off value of 0.50 [44] with the lowest AVE of 0.69. These results demonstrate the inter-item reliability and convergent validity of the measures. Moreover, the AVE of each construct exceeds the intercorrelations of the construct with the other constructs in the model, in support of discriminant validity [44, 46]. Additionally, the discriminant validity can also be assessed by inspecting the cross-loadings, which are not substantial in magnitude compared with the loadings [43, 47, 48].

Structural model and hypothesis testing. The explanatory power of the research model was evaluated by looking at the $\mathrm{R}^{2}$ value in the dependent variable - perceived pleasure of navigation. The $\mathrm{R}^{2}$ value indicates that the research model explained $37.2 \%$ of the variance for perceived pleasure of navigation.

Hypothesis 1 is significant, suggesting that an individual who feels ease of orientation in web services is more likely to perceive navigating web services as enjoyable. Hypothesis 2 is also significant, indicating that an individual who is able to focus on his/her primary task at hand when using web services is also more likely to feel ease of orientation in web services. Hypothesis 5 is significant, suggesting that an individual with a poor physical health status is less likely to feel ease of orientation in the web. In addition, Hypothesis 7 is supported, indicating that an individual who does physical exercises regularly is more likely to perceive navigating web services as enjoyable. The significance level for Hypothesis 3 is $p<0.1$, which is close to the conventional significance level. Given that the sample size is small, this relationship has the potential to be significant if the sample size is larger. 
Most hypotheses are supported by the data collected in this study. Although hypothesis 4 and hypothesis 8 are not supported, the direction of the effects is consistent as hypothesized. One plausible explanation for the two insignificant results lies in the small sample size used in this study. With respect to hypothesis 6 , a likely explanation for the insignificant result is as follows. It is widely believed that moderate-intensity physical exercise is good for health. In other words, if an individual does moderateintensity physical exercise regularly, s/he would be healthier than would otherwise be. However, it will take a longer period of time for the influence of physical exercises on an individual's health status to show up.

Control variables. Further analysis was carried out to assess the impacts of the control variables, in order to make sure the significant results were not due to covariation with these variables. The demographic information (gender, age, education, marital status, and employment) acts as control variables. After adding the control variables into the research model, the significance level for the relationships in the research model are similar as before (they only change very slightly). The significant paths are still significant and the insignificant paths remain insignificant. None of the control variables have a significant effect on the dependent variable. These results suggest that the research model is stable and independent of control variables.

\section{Discussion}

This study has many research implications. It is one of the first to explore in an interdisciplinary manner the potential to combine objective biochemical health measurements, self-reported physical activity, and perceptions of user experience. The findings that a user's focused attention facilitates feeling of ease of orientation in web usage and that the perceived ease of orientation influences a user's perception of navigating the web as more pleasurable, were expected and in line with previous findings [cf. 28].

However, the results, which relate to the role of physical health status and physical activity level for user experience perception, are novel. This study shows that the user experience of individuals with a high risk for type 2 diabetes differs according to their physical health status and amount of physical activity. Those with better lipid homeostasis (better physical health status) are more likely to feel ease of orientation in their web usage, and those are more frequent in their physical exercise are more likely to perceive pleasure in navigating the web. This relationship between health and orientation in the web as well as between physical activity and web navigation is an interesting finding, and there may be a natural explanation for it. After all, since a human is a psychosomatic whole, health and psychology are necessarily related, and navigating the web, at least ideally speaking, is similar to performing a physical activity.

The practical implications of these findings are important. Healthcare professionals and service providers in public and private sectors, business people, and software practitioners could, and should, modify their design approaches and business strategies based on them. As a societal implication, better user experiences should be provided for individuals whose health status is poor or who are physically less active. Provision of tailored and/or personalized solutions could improve these experiences. 
Admittedly, there are limitations in this explorative study. The participants were mostly over 60 years of age, and the greatest relative increase in type 2 diabetes prevalence is expected to be in the over-65 age group [49]. Cross-validation is needed with a younger population as well as with other groups of people, other than individuals with a high risk for type 2 diabetes. Seventy-two percent of the participants were women, which might reflect the previous findings that women are generally more health-oriented than men [50], or that women are more likely than men to participate in health promotion programs [51, 52]. This being said, from a health promotion perspective, it is important for more men to participate in this type of interventions. In general, gender differences in using such systems earn more attention. Besides the participants' physical health, their knowledge of type 2 diabetes and familiarity with web-based intervention(s) are likely to affect their perceptions of ease of orientation and navigational pleasure as well. Also, because all participants were self-selected volunteers, they may be more receptive to using new technologies and perhaps also more active in their daily lives.

There were also some methodological limitations. The study relied partly on selfreported survey data. Self-reported levels of physical activity are usually over-estimated, and we had no means to adjust for this. The sample size was relatively small, so larger studies would be needed to replicate and confirm the findings. Because of the crosssectional nature, longitudinal studies would be needed to enable studying sustainable change. Also, the approach adopted here was exploratory as all the topics were assessed with one or only a few questions. For these reasons, repetition of studies is warranted in future work. Adding some basic neuro-IS sensors to the study setting would be an interesting opportunity.

\section{Conclusion}

This article sought to explore the influence of one's physical health and physical activity on a web experience. User experience perceptions were investigated in relation to the self-reported amount of physical exercise and changes in lipid homeostasis. The results of the study demonstrate that perceived user experience of individuals at high risk for type 2 diabetes differs according to their physical health status and amount of physical activity. Those with a better physical health status are more likely to feel ease of orientation in their web usage, and those who take more frequent regular physical exercise are more likely to perceive pleasure in navigating the web. These results open up a new avenue of research. Taking into consideration the status of a user to render customized web-based services in order to increase the chance of intervention success is of growing importance, and utilizing objective physical measures and self-reports instruments provides a new pragmatic approach to monitor and quantify users on par with sensory technology. A new design paradigm and new business models for developing software, systems, and services based on end-users' physical health and physical activity should now be developed. 


\section{References}

1. Danaei G, Finucane MM, Lu Y, Singh GM, Cowan MJ, Paciorek CJ et al. (2011) "National, regional, and global trends in fasting plasma glucose and diabetes prevalence since 1980: systematic analysis of health examination surveys and epidemiological studies with 370 country-years and 2.7 million participants", Lancet, 378(9785), pp. 31-40.

2. WHO (1999) Definition, diagnosis and classification of diabetes mellitus and its complications. Part 1: Diagnosis and classification of diabetes mellitus, Geneva, Switzerland: World Health Organization (WHO/NCD/NCS/99.2)

3. Uusitupa, M., Tuomilehto, J. and Puska, P. (2011) "Are we really active in the prevention of obesity and type 2 diabetes at the community level?" Nutrition, Metabolism and Cardiovascular Diseases, 21(5), pp. 380-289.

4. Farmer, A. J., Levy, J. C. and Turner, R. C. (1999) "Knowledge of risk of developing diabetes mellitus among siblings of type 2 diabetes patients", Diabetic Medicine, 16(3), pp. 233-237.

5. Tuomilehto, J., Lindström, J., Eriksson, J.G., Valle, T.T., Hämäläinen, H., Ilanne-Parikka, P., KeinänenKiukaanniemi, S., Laakso, M., Louhenranta, A., Rastas, M., Salminen, P. and Uusitupa, M. (2001) "Prevention of type 2 diabetes mellitus by changes in lifestyle among subjects with impaired glucose tolerance", The New England Journal of Medicine, 344, pp. 1343-50.

6. van Esch, S.C., Cornel, M.C. and Snoek, F.J. (2006) "Type 2 diabetes and inheritance: what information do diabetes organizations provide on the Internet?", Diabetic Medicine, 23(11), pp. 1233-1238.

7. Satterfield, D., Jenkins, C., Bodnar, B., Constance, A. and Sisson, E. (2008) "Diabetes education and public health", Diabetes Educator, 34(1), pp. 45-48.

8. Lustria, M.L., Cortese, J., Noar, S.M. and Glueckauf, R.L. (2009) "Computer-tailored health interventions delivered over the Web: review and analysis of key components", Patient Education and Counseling, 74(2), pp. 156-173.

9. Yap, T.L. and Davis, L.S. (2008) "Physical activity: the science of health promotion through tailored messages", Rehabilitation Nursing, 33(2), pp. 55-62.

10. Hawkins, R.P., Kreuter, M., Resnicow, K., Fishbein, M. and Dijkstra, A. (2008) “Understanding tailoring in communicating about health", Health Education Research, 23(3), pp. 454-466.

11. Rimer, B.K. and Kreuter, M.W. (2006) "Advancing tailored health communication: A persuasion and message effects perspective", Journal of Communication, 56, pp. 184-201.

12. Enwald, H. P. K. and Huotari, M.-L. A. (2010) "Preventing the obesity epidemic by second generation tailored health communication: an interdisciplinary review", Journal of Medical Internet Research, 12(2), e24.

13. Enwald H., Niemelä R., Keinänen-Kiukaanniemi S., Leppäluoto J., Jämsä T., Herzig K.H., OinasKukkonen H. and Huotari M.L. (2012) "Human information behaviour and physiological measurements as a basis to tailor health information. An explorative study in a physical activity intervention among prediabetic individuals in Northern Finland", Health Information and Libraries Journal, 29(2), pp. 131140

14. Enwald H., Kortelainen T., Leppäluoto J., Keinänen-Kiukaanniemi S., Jämsä T., Oinas-Kukkonen H., Herzig K.H. and Huotari M.L. (2013) "Perceptions of fear appeal and preferences for feedback in tailored health communication. An explorative study among prediabetic individuals", Information Research: an international electronic journal, 18(3), paper 584.

15. Oinas-Kukkonen, H. (2013) "A foundation for the study of behavior change support systems", Personal and ubiquitous computing, 17(6), pp. 1223-1235.

16. Kraft P, Drozd F and Olsen E. (2009) "ePsychology: designing theory-based health promotion interventions", Communications of the Association for Information Systems, 24, Article 24.

17. Hoffman, D. and Novak, T. (1997) "A New Marketing Paradigm for Electronic Commerce", The Information Society, 13, pp. 43-54.

18. Finneran, C. M., and Zhang, P. (2003) „A person-artifact-task (PAT) model of flow antecedents in computer-mediated environments", International Journal of Human-Computer Studies, 59, pp. 475-496.

19. Kamis, A., M. Koufaris, and T. Stern (2008) "Using an attribute-based DSS for user-customized products online: An experimental investigation", MIS Quarterly, 32(1), pp. 159-177. 
20. Oinas-Kukkonen, H. and Harjumaa, M. (2009) "Persuasive Systems Design: Key Issues, Process Model, and System Features", Communications of the Association for Information Systems, (24), Article 28, pp. 485-500.

21. Oinas-Kukkonen, H. (2000) "Balancing the vendor and consumer requirements for electronic shopping systems", Information Technology and Management, 1(1\&2), pp. 73-84.

22. Case, D.O. (2012) Looking for Information. A Survey of Research on Information Seeking, Needs, and Behavior. 3th edition. Bingley, UK: Emerald.

23. Csikszentmihalyi, M. (1977) Beyond Boredom and Anxiety. San Francisco, CA: Jossey-Bass.

24. Choi, D. H., Kim, J., and Kim S. H. (2007) "ERP training with a Web-based electronic learning system: The flow theory perspective", International Journal of Human-Computer Studies, 65, pp. 223-243.

25. Lu Y., Zhou T. and Wan B. (2009) "Exploring Chinese users' acceptance of instant messaging using the theory of planned behavior, the technology acceptance model, and the flow theory", Computers in Human Behavior, 25(1), pp. 29-39.

26. Jung Y., Perez-Mira B. and Wiley-Patton S. (2009) "Consumer adoption of mobile TV: Examining psychological flow and media content", Computers in Human Behavior, 25(1), pp. 123-129.

27. Hoffman, D. and Novak, T. (1996) "Marketing in Hypermedia Computer-Mediated Environments: Conceptual Foundations", Journal of Marketing, July, pp. 50-68.

28. Oinas-Kukkonen, H., Räisänen, T., Leiviskä, K., Seppänen, M. and Kallio, M. (2009) "Physicians' User Experiences of Mobile Pharmacopoeias and Evidence-Based Medical Guidelines", International Journal of Healthcare Information Systems and Informatics, 4(2), pp. 57-68.

29. Parvinen, P., Oinas-Kukkonen H. and Kaptein M. (2015) "E-selling: A new avenue of research for service design and online engagement", Electronic Commerce Research and Applications.

30. Adamo, K.B., Prince, S.A., Tricco, A.C., Connor-Gorder, S. and Tremblay, M. (2009) "A comparison of indirect versus direct measures for assessing physical activity in the pediatric population: a systematic review", International Journal of Pediatric Obesity, 4(1), pp. 2-27.

31. Cocker De, K., Spittaels, H., Cardon, G., De Bourdeaudhuij, I. and Vandelanotte, C. (2012) "Web-based, computer-tailored, pedometer-based physical activity advice: development, dissemination through general practice, acceptability, and preliminary efficacy in a randomized controlled trial", Journal of Medical Internet Research, 14(2), e53.

32. Plotnikoff, R.C. and Karunamuni, N. (2011) "Steps towards permanently increasing physical activity in the population", Current Opinion in Psychiatry, 24, pp. 162-167.

33. Short, C.E., James, E.L., Plotnikoff, R.C. and Girgis, A. (2011) "Efficacy of tailored-print interventions to promote physical activity: a systematic review of randomized trials", International Journal of Behavioral Nutrition and Physical Activity, 8, 113.

34. Broekhuizen, K., Kroeze, W., Poppel, M.N.M. van Oenema, A. and Brug, J. (2012) “A systematic review of randomized controlled trials on the effectiveness of computer-tailored physical activity and dietary behavior promotion programs: an update", Annals of Behavioral Medicine, 44, pp. 259-286.

35. Kroeze, W., Werkman, A. and Brug, J. (2006) "A systematic review of randomized trials on the effectiveness of computer-tailored education on physical activity and dietary behaviors", Annals of Behavioral Medicine, 31(3), pp. 205-223.

36. Venkatesh, V., Morris, M. G., Davis, G. B., and Davis, F. D. (2003) "User Acceptance of Information Technology: Toward a Unified View", MIS Quarterly, 27(3), pp. 425-478.

37. Knowler WC, Barrett-Connor E, Fowler SE, Hamman RF, Lachlin JM, Walker EA, Nathan DM (Diabetes Prevention Program Research Group) (2002) "Reduction in the incidence of type 2 diabetes with lifestyle intervention or metformin", The New England Journal of Medicine, 346, pp. 393-403.

38. Blair S.N. and Morris J. N. (2009). Healthy Hearts - and the universal benefits of being physically active: Physical activity and health. Annals of Epidemiology, 19, 253-256.

39. Vainionpää, A., Korpelainen, R., Kaikkonen, H., Knip, M., Leppäluoto, J. and Jämsä, T. (2007) "Effect of impact exercise on physical performance and cardiovascular risk factors", Medicine \& Science in Sports \& Exercise, 39, pp. 756-63.

40. Herzig KH, Ahola R, Leppäluoto J, Jokelainen J, Jämsä T, Keinänen-Kiukaanniemi S. (2013) "Light physical activity determined by a motion sensor decreases insulin resistance, improves lipid homeostasis and reduces visceral fat in high risk subjects: PreDiabEx study RCT", International Journal of Obesity, 2013 Nov 28, doi:10.1038/ijo.2013.224. 
41. Tucker J.M., Welk G.J. and Beyler N.K. (2011) "Physical activity in U.S.: Adults compliance with the Physical Activity Guidelines for Americans", American Journal of Preventive Medicine, 40(4), pp. 454461.

42. Ringle, C.M., Wende, S., and Will A. (2005). SmartPLS Version 2.0 M2, http://www.smartpls.de.

43. Chin, W. W. (1998) "The Partial Least Squares Approach to Structural Equation Modeling," in G. A. Marcoulides (Ed.) Modern Methods for Business Research. Mahway, NJ,: Lawrence Erlbaum Associates Inc., pp. 295-336.

44. Fornell, C., and Larcker, D. F. (1981) "Evaluating Structural Equation Models with Unobservable Variables and Measurement Error: Algebra and Statistics", Journal of Marketing Research, 18(3), pp. 383-388.

45. Werts, C.E., Linn, R.L., and Jöreskög, K.G. (1974) "Intraclass Reliability Estimates: Testing Structural Assumptions", Educational and Psychological Measurement, 34(1), pp. 25-33.

46. Gefen, D., Straub, D. W., Boudreau, M-C. (2000) "Structural Equation Modeling Techniques and Regression: Guidelines for Research Practice", Communications of the Association for Information Systems, 4(7), pp. 1-79.

47. Fornell, C., and Bookstein, F. L. (1982) “Two Structural Equation Models: LISREL and PLS Applied to Consumer Exit-Voice Theory," Journal of Marketing Research, 19(4), pp. 440-452.

48. Hulland, J. (1999) "Use of Partial Least Squares (PLS) in Strategic Management Research: A Review of Four Recent Studies”, Strategic Management Journal, 20(2), pp. 195-204.

49. Wild, S., Roglic, G., Green, A., Sicree, R. and King, H. (2004) "Global prevalence of diabetes: estimates for the year 2000 and projections for 2030", Diabetes Care, 27(5), pp. 1047-1053.

50. Bech-Larsen, T. and Scholderer, J. (2010) "Functional foods in Europe: consumer research, market experiences and regulatory aspects", Trends in Food Science and Technology, 18, pp. 231-234.

51. Assaf, A. R., Parker, D., Lapane, K. L., Coccio, E., Evangelou, E. and Carleton, R. A. (2003) "Does the Y chromosome make a difference? Gender differences in attempts to change cardiovascular disease risk factors", Journal of Women's Health, 12(4), pp. 321-330.

52. Goh, J. M. and Agarwal, R. (2008) "Taking charge of your health: the drivers of enrollment and continued participation in online health intervention programs", Proceedings of the 41st Hawaii International Conference on System Sciences 2008. 